\title{
Caries Experience and Oral Health-related Factors of Kuwaiti Preschool Children and their Mothers: A Pilot Study
}

\author{
Fatemah AAM Husain ${ }^{1}$, Abrar N Alanzi²
}

\begin{abstract}
Aim: The objective of this study was to investigate the association between the caries experience and oral-health-related behavior of Kuwaiti preschool children and their mothers.

Materials and methods: A convenience sample of 84 participants ( 42 child-mother pairs) was selected. Data regarding children's and mothers' demographics, oral hygiene practices, and dietary habits were obtained by questionnaires. Oral clinical examinations were carried out on the participant children and mothers to determine their caries experience (decayed, missing, and filled teeth index-dmft/DMFT).

Results: An estimated $19 \%$ of children were caries-free and $66 \%$ of mothers have untreated caries. The mean dmft index of the preschool children was $3.90 \pm 2.9$, and the mean DMFT index of their mothers was $12.38 \pm 5.4$. Mothers' untreated caries was significantly associated with their children's untreated caries $(r=0.183, p<0.05)$. No correlation was found between the brushing frequencies of children and their mothers $(p=0.582)$. High consumption of sugary snacks and sugary beverages was detected among the children and mothers with a significant association $(p<0.05)$. The mean $\mathrm{dmft}$ of the children was found to be significantly lower among the young mothers, less than 30 years, $(2.4 \pm 2.1)$ compared to that among the mothers older than 30 years $(4.3 \pm 2.9, p<0.05)$.

Conclusion: There was a high prevalence of early childhood caries in the preschool children studied. A positive correlation was found between the dental caries experience and sugar consumption of the Kuwaiti preschool children and those of their mothers.

Clinical significance: The oral health status and dietary habits of mothers are potentially significant risk factors for the development of early childhood caries in their children. Pediatric dentists need to identify the main caries risk factors in their community in order to implement appropriate preventive dental care and educational programs.
\end{abstract}

Keywords: Dental caries, Oral health, Preschool children.

International Journal of Clinical Pediatric Dentistry (2019): 10.5005/jp-journals-10005-1652

\section{INTRODUCTION}

Early childhood caries (ECC) is a major worldwide oral health problem that affects preschool children. 'The American Academy of Pediatric Dentistry defines ECC as the "presence of one or more decayed, missing or filled tooth surfaces in any primary tooth" in children aged 71 months or younger. ${ }^{2}$ There were numerous terminologies used to illustrate the condition such as rampant caries, baby bottle tooth decay, nursing caries, and milk bottle syndrome. A review of the literature found that the prevalence of ECC in most developed countries was $1-12 \%$, while the prevalence in developing countries has been found to be high (up to $70 \%$ ). ${ }^{3}$ In Kuwait, the prevalence of ECC in 4- and 5-year-old children was $68 \%$ and $76 \%$, respectively, ${ }^{4}$ which was similar to the prevalence reported in some Middle Eastern countries. ${ }^{5,6}$ The high prevalence of ECC in preschool children remains a major clinical problem for oral health professionals because it has a negative impact on the child, family, and community. ${ }^{1}$

Dental caries is a multifactorial disease that results from critical interactions among a susceptible tooth surface, cariogenic bacteria, and exposure to fermentable carbohydrates. ${ }^{7}$ In young children, there are distinctive risk factors for ECC, including the presence of white spot lesions, increased counts of mutans streptococci, a high frequency of sugary intake, and other socioeconomic factors. ${ }^{7}$ A young child's dental environment is complex because their mothers' dental knowledge, attitudes, beliefs, and practices affect the child's oral condition. ${ }^{8,9}$ Mothers are usually the main caregivers during early childhood and are the key persons in their family for the determination of dental health behavior of young children. ${ }^{10}$ Recent research found that mothers' oral health status is a strong
1,2 Department of Developmental and Preventative Sciences, Faculty of Dentistry, Kuwait University, Safat, Kuwait

Corresponding Author: Fatemah AAM Husain, Department of Developmental and Preventative Sciences, Faculty of Dentistry, Kuwait University, Safat, Kuwait, Phone: +965 99323711, e-mail: fatmahusain90@gmail.com

How to cite this article: Husain FAAM, Alanzi AN. Caries Experience and Oral Health-related Factors of Kuwaiti Preschool Children and their Mothers: A Pilot Study. Int J Clin Pediatr Dent 2019;12(4):283-287.

Source of support: Nil

Conflict of interest: None

predictor of the oral health status of their young children. ${ }^{11}$ Also, mothers' educational level showed a significant association with dental caries in their preschool children. ${ }^{12,13}$

The increasing trend of dental caries experience of the preschool children in Kuwait warrants further attention to investigate the caries-related factors in their mothers. Therefore, this pilot study aimed to investigate the association between the caries experience and oral health-related behavior of a selected group of Kuwaiti preschool children and their mothers. The results will determine the need and guide the planning of a large-scale project and preventive programs.

\section{Materials and Methods}

The research protocol was approved by Kuwait University Health Sciences Centre Ethical Committee. A random selection of one big 
kindergarten school in Hawalli governate, Kuwait, was made. Onehundred and twenty children, aged 3-5 years, were enrolled in the school and were invited to participate in the study. The informed consents were sent to their mothers by classroom teachers. The selection was based on the following criteria: 3-5-year-old preschool children with ASA physical status I or II, and mothers who were the primary caregivers. The study included two parts: questionnaires and clinical examinations.

Data on the demographic information, oral hygiene practices, and dietary habits were collected by orally administered questionnaires. They were completed by the mothers on the same visit as the clinical examinations were performed. The questionnaire consisted of two parts and was not expected to take longer than 10 minutes to complete. Both parts had 10 questions. The first part had questions related to the child's age, oral hygiene practices, and sugar consumption. The second part had questions regarding the mother's age, education, oral hygiene practices, and dietary habits.

The clinical examinations were carried out on the participant children and their mothers at school premises (nurse's room). All examinations were conducted by a single calibrated examiner using a mobile dental chair with a portable light (Sun-led Classic, BPR Swiss, Switzerland). Dental caries experience was assessed using the decayed, missing, and filled teeth (DMFT) index. ${ }^{14}$ After the examination, all participant children received a fluoride varnish.

\section{Statistical Analysis}

All data were entered and analyzed using the Statistical Package for the Social Sciences version 20 software (SPSS Inc, Chicago, IL, USA). Descriptive statistics (mean, frequencies, percentage) were performed. A Chi-square test was used for nominal or ordinal variables. Analysis of variance (ANOVA) was used to determine the difference in the dental caries experience ( $\mathrm{dmft}$ ) and to compare children's dmft by mothers' dmft, mothers' demographic factors, and oral-health-related factors. A $p$ value of less than 0.05 was considered statistically significant.

\section{Results}

A total of 42 mother-child dyads participated and completed this study. There were 13 boys and 29 girls. Children's age ranged from 3-5 years. The mothers of those children varied in their age between 20 years and 50 years with a mean age of $33.9 \pm 9.4$. The distribution of the demographic variables, oral hygiene factors, and dietary habits of the participant children and mothers are presented in Tables 1 and 2. Almost two-thirds of the participant mothers (64.3\%) had college education, and only $21.4 \%$ of them were unemployed.

\section{Oral Health Status}

The mean dmft index for the preschool children was $3.90 \pm 2.9$, and the mean DMFT index of their mothers was $12.38 \pm 5.4$ (Table 3). Only $19 \%$ of the children were caries-free, and $28 \%$ had filled teeth. Two-thirds of the mothers (66.6\%) had untreated caries, and about one-third (28.4\%) had dental fillings. Mothers' untreated caries was significantly associated with their children's untreated caries $(r=0.183, p<0.05)$.

\section{Oral Hygiene Practices}

More than half (54.8\%) of the children brushed their teeth at least twice a day, while most of the mothers $(90.5 \%)$ brushed their teeth twice a day or more. The majority of the children performed tooth brushing with the help of their mothers (74\%) and used fluoridated
Table 1: Demographic features, oral hygiene practices, and dietary habits of the participant children

\begin{tabular}{|c|c|c|}
\hline & Number $(n=42)$ & Percentage \\
\hline \multicolumn{3}{|l|}{ Child age } \\
\hline 4 years & 20 & 47.6 \\
\hline 5 years & 22 & 52.4 \\
\hline \multicolumn{3}{|l|}{ Gender } \\
\hline Male & 13 & 30.9 \\
\hline Female & 29 & 69.1 \\
\hline \multicolumn{3}{|c|}{ Child's toothbrushing frequency } \\
\hline$<$ Once/day & 19 & 45.2 \\
\hline >Twice/day & 23 & 54.8 \\
\hline \multicolumn{3}{|c|}{ Child's frequency of sugary snack intake } \\
\hline$<$ Once/day & 3 & 7.2 \\
\hline >Twice/day & 39 & 92.8 \\
\hline \multicolumn{3}{|c|}{ Chid's frequency of sugary beverages } \\
\hline$<$ Once/day & 8 & 19.1 \\
\hline >Twice/day & 34 & 80.9 \\
\hline \multicolumn{3}{|c|}{ Child's frequency of soft drinks } \\
\hline$<$ Once/day & 27 & 64.3 \\
\hline >Twice/day & 15 & 35.7 \\
\hline \multicolumn{3}{|c|}{ Previous dental visits } \\
\hline Never & 19 & 45.2 \\
\hline Once & 7 & 16.7 \\
\hline Twice or more & 16 & 38.1 \\
\hline \multicolumn{3}{|c|}{ Reason for previous dental visit } \\
\hline Check up & 11 & 26.2 \\
\hline Toothache & 31 & 73.8 \\
\hline
\end{tabular}

toothpaste (76\%). Only $7 \%$ of the mothers used dental floss regularly, and almost a half of them (48.6\%) had never used it. The results showed no statistically significant correlation between the brushing frequencies of children and mothers ( $p=0.582$ ). Also, no significant association was found between children's tooth brushing frequency and their caries experience ( $p=0.141)$.

\section{Dietary Habits}

High consumption of sugary snacks and sugary beverages was found among the children (92.8\%, 80.9\%, respectively) and mothers (73.8\%,52.4\%, respectively). Regarding the intake of soft drinks, most children (64.3\%) and mothers (80.9\%) never or rarely used them on a daily basis. There was a strong association in the use of sugary food and beverages, including soft drinks between the mother and the child $(p<0.05)$. Also, a significant association was shown between the children's caries experience ( $\mathrm{dmft}$ ) and their sugar consumption $(p<0.05)$.

\section{Dental Visits}

In all, $45 \%$ of children had never visited a dentist in their life. Those children had lower mean $\mathrm{dmft}(3.1 \pm 3.6)$ than those who had one $(4.4 \pm 3.5)$ or more visits $(4.8 \pm 2.2)$. The most common reason for previous dental visits was toothache (73.8\%). There was not a significant association between a child's dental visit and his/her mother's dental visits $(p=0.114)$. When asked about the preventive care methods, only one mother reported that her child had received topical fluoride application in a dental clinic. None of the children received dental sealants in their primary teeth. 
Table 2: Demographic features, oral hygiene practices, and dietary habits of the participant mothers

\begin{tabular}{|c|c|c|}
\hline & Number $(n=42)$ & Percentage \\
\hline \multicolumn{3}{|l|}{ Mother's age (years) } \\
\hline $20-29$ & 8 & 19.1 \\
\hline $30-39$ & 26 & 61.8 \\
\hline $40-49$ & 8 & 19.1 \\
\hline \multicolumn{3}{|l|}{ Mother's education level } \\
\hline High school/GED or less & 15 & 35.7 \\
\hline College graduate or more & 27 & 64.3 \\
\hline \multicolumn{3}{|l|}{ Mother's occupation } \\
\hline Unemployed & 9 & 21.4 \\
\hline Employee/non-professional & 13 & 31.0 \\
\hline Employee/professional & 20 & 47.6 \\
\hline \multicolumn{3}{|c|}{ Mother's toothbrushing frequency } \\
\hline$<$ Once/day & 4 & 9.5 \\
\hline$>$ Twice/day & 38 & 90.5 \\
\hline \multicolumn{3}{|c|}{ Mother's frequency of sugary snack intake } \\
\hline$<$ Once/day & 11 & 21.2 \\
\hline >Twice/day & 31 & 73.8 \\
\hline \multicolumn{3}{|c|}{ Mother's frequency of sugary beverages } \\
\hline$<$ Once/day & 20 & 47.6 \\
\hline >Twice/day & 22 & 52.4 \\
\hline \multicolumn{3}{|c|}{ Mother's frequency of soft drinks } \\
\hline$<$ Once/day & 34 & 80.9 \\
\hline > Twice/day & 8 & 19.1 \\
\hline \multicolumn{3}{|l|}{ Mother's previous dental visits } \\
\hline Never & 0 & 0 \\
\hline Once & 16 & 38.1 \\
\hline Twice or more & 26 & 61.9 \\
\hline
\end{tabular}

Table 3: Decayed, missing, and filled teeth index of the preschool children (dmft) and their mothers (DMFT)

\begin{tabular}{lll}
\hline & $\begin{array}{l}\text { Preschool children } \\
(n=42), \text { mean } \pm S D\end{array}$ & $\begin{array}{l}\text { Mothers }(n=42), \\
\text { mean } \pm S D\end{array}$ \\
\hline Dmft/DMFT & $3.90 \pm 2.9$ & $12.38 \pm 5.4 \mathrm{~s}$ \\
$\mathrm{dt} / \mathrm{DT}$ & $3.20 \pm 2.2$ & $6.60 \pm 5.5$ \\
$\mathrm{mt} / \mathrm{MT}$ & $0.12 \pm 1.1$ & $1.28 \pm 1.2$ \\
$\mathrm{ft} / \mathrm{Ft}$ & $0.58 \pm 1.5$ & $4.50 \pm 3.81$ \\
\hline
\end{tabular}

\section{Mother's Demographics}

The mean dmft of the children was found to be significantly lower among the young mothers, less than 30 years, $(2.4 \pm 2.1)$ compared to that among the mothers older than 30 years $(4.3 \pm 2.9$, $p<0.05$, Fig. 1). The association between the dental caries experience of the preschool children and their mothers' educational level existed but it was not statistically significant $(p=0.08)$. The effect of mothers' occupation on the children's caries experience was not evident (0.189).

\section{Discussion}

This is the first exploratory study to investigate the possible association between the caries experience and the oral health habits of Kuwaiti preschool children and their mothers. The results

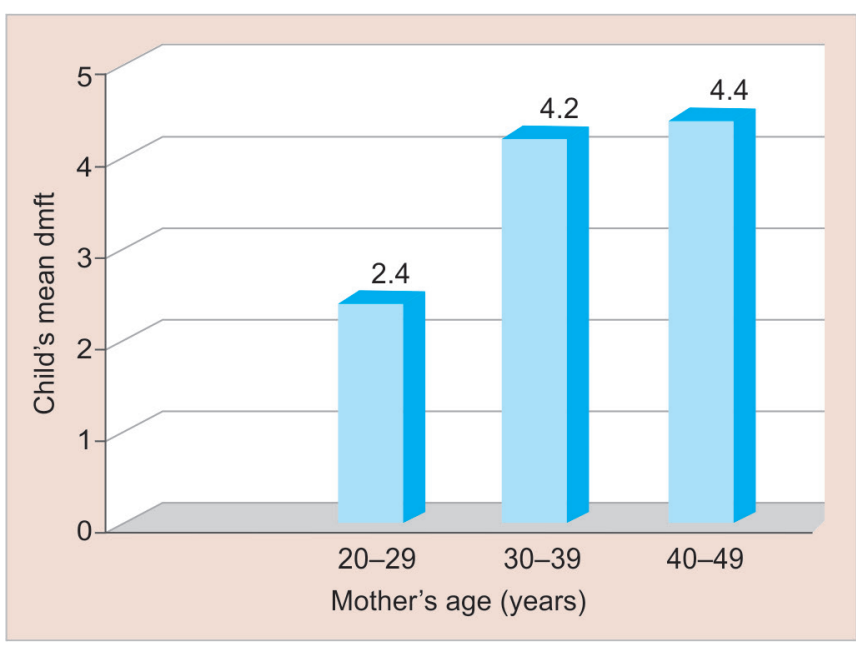

Fig. 1: The mean dmft of the participant children according to the age of their mothers

of the study will pave the way for conducting a large-scale research in Kuwait.

Early childhood caries was found in $80 \%$ of the children in this study. This prevalence is higher than that reported in Saudi Arabia and Jordan (73\% and $67 \%$ of children in similar age group respectively). ${ }^{15,16}$ However, it was similar to the prevalence observed previously in Kuwait by Vigild et al. ${ }^{17}$ An increase in caries experience figures of the primary dentition had been reported between 1982 and 2000. ${ }^{18}$ The proportion of caries-free children in primary dentition has been reported to be $14 \%$ in $2002,{ }^{18}$ which was not different from the finding of this study. There is a schoolbased oral health program (SOHP) in Kuwait, which provides oral health education, prevention, and treatment to the school children. Recently, the SOHP is giving more emphasis to the youngest age group by increasing the efforts on their preventive care. ${ }^{19}$ Before that, no oral health programs have been implemented for targeting very young children in Kuwait. ${ }^{20}$

The results of the present study indicated that the overall dental caries experience was slightly higher (3.9) than what was documented previously in Kuwait (2.9) by Murtomaa et al. ${ }^{21}$ The mean DMFT reported for the mothers in our sample was similar to what was found in Saudi Arabia. ${ }^{22}$ The association between the caries experience of the children and their mothers was evident in our sample. Mothers' dental caries status has been correlated to their young children's dental caries status in previous studies. ${ }^{23-25}$ Also, the maternal untreated dental caries was found to double the odds of children's untreated dental caries. ${ }^{26}$ Therefore, mothers' oral health condition is an important risk indicator for their preschool children.

In our sample, the children's oral health behavior did not show any significant association with their dental caries experience. This finding was in agreement with the results of Okada et al. study. ${ }^{27}$ Although the correlation between the mothers' oral health habits and their children's oral health habits was marked in previous studies, ${ }^{27-29}$ this association failed to emerge in this study. The effect of toothbrushing habits might have been overwhelmed by the effect of dietary habits since this variable was strongly associated with the caries experience. Also, in Kuwait, many working mothers rely on nannies and babysitters to look after their children, including the child's dental care. The oral health status of other primary caregivers should be explored when implementing a future research. 
High consumption of sugary food and beverages was found among the participating children and mothers with clear evidence linking their dietary habits to their caries experience. The present study supports the earlier studies, which showed that the frequent consumption of sugary snacks and beverages increases the risk for dental caries. ${ }^{30,31}$ A significant association existed in the sugar intake between the children and their mothers in our sample. This was probably because they were readily available in front of the child when his/her mother consumed them. Sweets may also well have been used as a reward by the parents. This leads to the establishment of a habit that persists even when a child gets older. ${ }^{32}$

The findings of our study showed that the caries experience of children who never visited a dentist was lower than that of children who had one or more dental visits. It can be explained by the fact that mothers had taken their children to the dentist because of a toothache rather than for a regular check-up. There was not a significant association between the mothers' dental visits and their children's dental visits $(p=0.114)$, which was consistent with the findings of Bozorgmehr et al. study. ${ }^{33}$ Many parents may not be aware of the importance of primary teeth as they mistakenly believe that these teeth are temporary. Therefore, the parents may visit the dentist when their child complains of dental pain and for their own dental problems.

The caries experience of the preschool children of young mothers, less than 30 years, in this investigation was found to be lower compared to that of the children of older mothers. A young Kuwaiti mother tends to have his/her first and second child before the age of 30 . So, it is more likely that the mother gives more attention to her first-born children, concerning the preventive behavior and the control of dietary sugars in particular. The opposite is true for the high-birth-order children. ${ }^{34}$ Consequently, the lowest caries experience occurred in children whose birth order was less than three. Maternal education was found to have a crucial role in their children dental care. ${ }^{35}$ Although a high dental caries level in the preschool children was associated with the low educational level of the mothers, ${ }^{13}$ no clear association was found in the present study and this finding was in line with Rajab et al. study. ${ }^{36}$

Even though the present study demonstrated a significant relationship in the caries experience and sugar consumption between the preschool children and their mothers, there are some shortcomings. This study was conducted in a convenience sample and the children included in this investigation were living in one governate, reducing the generalizability of the results. Also, not all possible dental caries risk and protective factors were assessed and controlled for in this study (e.g., salivary flow rate, level of mutans streptococci, fathers' demographics). On the basis of the current findings, the implementation of future study with a larger sample size involving all governates is required to give a representative picture of the national caries experience and associated factors.

\section{Conclusion}

There was a clear correlation between the dental caries experience and sugar consumption of the Kuwaiti preschool children and their mother's caries experience and sugar consumption. However, no correlation was found between the oral health habits of the children and those of their mothers. The high prevalence of early childhood caries emphasizes an urgent need for comprehensive preventive programs covering all preschool children and an intensive oral health education covering all parents of the young children.

\section{Clinical Significance}

The oral health status and dietary habits of mothers are potentially significant risk factors for the development of early childhood caries in their children. Pediatric dentists need to identify the main caries risk factors in their community in order to implement appropriate preventive dental care and educational programs.

\section{References}

1. Sukumaran A, Pradeep SA. Early childhood caries: prevalence, risk factors, and prevention. Front Pediatr 2017 Jul 18;5:157. DOI: 10.3389/ fped.2017.00157.

2. Drury T, Horowitz A, et al. Diagnosing and reporting early childhood caries for research purposes. J Public Health Dent 1999;59(3):192-197. DOI: 10.1111/j.1752-7325.1999.tb03268.x.

3. Congiu G, Campus G, et al. Early childhood caries (ECC) prevalence and background factors: a review. Oral Health Prev Dent 2014;12(1): 71-76.

4. Al-Mutawa SA, Shyama M, et al. Dental caries experience of Kuwaiti school children. Community Dent Health 2006 Mar;23(1):31-36.

5. Azizi Z. The prevalence of dental caries in primary dentition in 4to 5 -year-old preschool children in northern Palestine. Int J Dent 2014;2014:839419. DOI: 10.1155/2014/839419.

6. El-Nadeef MA, Hassab $\mathrm{H}$, et al. National survey of the oral health of 5 -year-old children in the United Arab Emirates. East Mediterr Health J 2010 Jan;16(1):51-55. DOI: 10.26719/2010.16.1.51.

7. Harris R, Nicoll AD, et al. Risk factors for dental caries in young children:a systematic review of the literature. Community Dent Health 2004 Mar; 21(Suppl 1):71-85.

8. Crawford A, Lennon M. Dental attendance patterns among mothers and their children in an area of social deprivation. Community Dental Health 1992 Sep;9(3):289-294.

9. Grytten J, Rossow I, et al. Longitudinal study of dental health behaviour and other caries predictors in early childhood. Community Dent Oral Epidemiol 1988 Dec;16(6):356-359. DOI: 10.1111/j.16000528.1988.tb00581.x.

10. Okada M, Kawamura M, et al. Influence of oral health attitude of mothers on the gingival health of their school age children. ASDC J Dent Child 2001 Sep-Dec;68(5-6):379-383; 303.

11. Dye BA, Vargas CM, et al. Assessing the relationship between children's oral health status and that of their mothers. J Am Dent Assoc 2011 Feb;142(2):173-183. DOI: 10.14219/jada.archive.2011.0061.

12. Dini EL, Holt RD, et al. Caries and its association with infant feeding and oral health-related behaviours in 3-4-year-old Brazilian children. Community Dent Oral Epidemiol 2000 Aug;28(4):241-248. DOI: 10.1034/j.1600-0528.2000.280401.x.

13. Chan SC, Tsai JS, et al. Feeding and oral hygiene habits of personal children in Hong Kong and their caregivers' dental knowledge and attitudes. Int J Pediatr Dent 2002 Sep;12(5):322-331. DOI: 10.1046/j.1365-263X.2002.00389.x.

14. American Dental Association. Proceedings of the Conference on the Clinical Testing of Cariostatic Agents, October 1968. Chicago, III: Council on Dental Research and Council on Dental Therapeutics, American Dental Association; 1972.

15. Al-Malik M, Holt R, et al. The relationship between erosion, caries and rampant caries and dietary habits in preschool children in Saudi Arabia. Int J Pediatr Dent 2001 Nov;11(6):430-439. DOI: 10.1046/j.09607439.2001.00308.x.

16. Sayegh A, Dini E, et al. Oral health, sociodemographic factors, dietary and oral hygiene practices in Jordanian children. J Dent 2005 May;33(5):379-388. DOI: 10.1016/j.jdent.2004.10.015.

17. Vigild $M$, Skougaard $M$, et al. Dental caries and dental fluorosis among 4-,6-,12-and 15-year-old children in kindergartens and public schools in Kuwait. Community Dent Health 1996 Mar;13(1):47-50.

18. Al-Mutawa S, Al-Duwairi Y, et al. The trend of dental caries experience of children in Kuwait. Dent News 2002;9(3):9-13. 
19. Ariga J, Al-Mutawa S, et al. School Oral Health Program in Kuwait. Med Princ Pract 2014;23(Suppl 1):43-46. DOI: 10.1159/000356504.

20. Morris R, Gillespie G, et al. Early childhood caries in Kuwait review and policy recommendations. East Mediterr Health J 1999 Sep;5(5): 1014-1022.

21. Murtomaa $\mathrm{H}$, Al-Zaabi $\mathrm{F}$, et al. Caries experience in a selected group of children in Kuwait. Acta Odontol Scand 1995 Dec;53(6):389-391. DOI: 10.3109/00016359509006006.

22. Mannaa A, Carlén A, et al. Dental caries and associated factors in mothers and their preschool and school children-A cross-sectional study. J Dent Sci 2013 Jun;8(2):101-108. DOI: 10.1016/j.jds.2012. 12.009 .

23. Ersin N, Eronat N, et al. Association of maternal-child characteristics as a factor in early childhood caries and salivary bacterial counts. J Dent Child 2006 May-Aug;73(2):105-111.

24. Smith R, Badner V, et al. Maternal risk indicators for childhood caries in an inner city population. Community Dent Oral Epidemiol 2002 Jun;30(3):176-181. DOI: 10.1034/j.1600-0528.2002.300303.x.

25. Ringelberg $M$, Matonski $G$, et al. Dental caries experience in three generations of families. J Public Health Dent 1974;34(3):174-180. DOI: 10.1111/j.1752-7325.1974.tb04000.x.

26. Weintraub J, Prakash $P$, et al. Mothers' caries increases odds of children's caries. J Dent Res 2010 Sep;89(9):954-958. DOI: 10.1177/002 2034510372891.

27. Okada M, Kawamura $M$, et al. Influence of parents' oral health behaviour on oral health status of their school children. Int J Pediatr Dent 2002 Mar;12(2):101-108. DOI: 10.1046/j.1365-263X.2002. 00338.x.
28. Sarnat $H$, Kagan A, et al. The relation between mothers attitude toward dentistry and the oral status of their children. Pediatr Dent 1984 Sep;6(3):128-131.

29. Sasahara H, Kawamura M, et al. Relationship between mothers' gingival condition and caries experience of their 3-year old children. Int J Pediatr Dent 1998 Dec;8(4):261-267. DOI: 10.1046/j.1365263x.1998.00091.x.

30. Hallett KB, O'Rourke PK. Social and behavioural determinants of early childhood caries. Aust Dent J 2003 Mar;48(1):27-33. DOI: 10.1111/j.1834-7819.2003.tb00005.x.

31. Ibrahim S, Nishimura $M$, et al. A longitudinal study of early childhood caries risk, dental caries and lifestyle. Pediatr Dent J 2009 Sep;19(2):174-180. DOI: 10.1016/S0917-2394(09)70171-5.

32. Rossow I, Kjaemes U, et al. Pattern of sugar consumption in early childhood. Community Dent Oral Epidemiol 1990 Feb;18(1):12-16. DOI: 10.1111/j.1600-0528.1990.tb00654.x.

33. Bozorgmehr E, Hajizamani A, et al. Oral health behavior of parents as a predictor of oral health status of their children. ISRN Dent May 8;2013; 741783. DOI: 10.1155/2013/741783.

34. Kinirons $M$, McCabe $M$. Familial And maternal factors affecting the dental health and dental attendance of preschool children. Community Dent Health 1995 Dec;12(4):226-229.

35. Thomas J, Startup R. Social influences on the dental health behaviour of 5 year-old. Health Educ J 1990 Sep;50(3):111-114. DOI: 10.1177/001789699105000303.

36. Rajab L, Peterson P, et al. Oral health behaviour of schoolchildren and parents in Jordan. Int J Pediatr Dent 2002 May;12(3):168-176. DOI: 10.1046/j.1365-263X.2002.00359.x. 